Faculdade de Medicina Veterinária e Zootecnia Departamento de Nutrição e Produção Animal na dieta de frangos de corte 


\section{Avaliação de diferentes planos nutricionais utilizando leveduras na dieta de frangos de corte}

Dissertação apresentada ao

Programa de Pós-Graduação em

Nutrição e Produção Animal da

Faculdade de Medicina Veterinária

e Zootecnia da Universidade de São

Paulo para obtenção do título de mestre em Ciências

\section{Departamento:}

Nutrição e Produção Animal

Área de concentração:

Nutrição Animal

Orientador:

Prof. Dr. Lúcio Francelino Araújo 
Autorizo a reprodução parcial ou total desta obra, para fins acadêmicos, desde que citada a fonte.

(Biblioteca Virginie Buff D'Ápice da Faculdade de Medicina Veterinária e Zootecnia da Universidade de São Paulo)

Avaliação de diferentes planos nutricionais utilizando leveduras na dieta de frangos de corte / Lara Santa Cruz Valadares. -- 2012

$$
39 \mathrm{f} \text {. }
$$

Dissertação (Mestrado) - Universidade de São Paulo. Faculdade de Medicina Veterinária e Zootecnia. Departamento de Nutrição e Produção Animal, Pirassununga, 2012.

Programa de Pós-Graduação: Nutrição e Produção Animal.

Área de concentração: Nutrição e Produção Animal.

Orientador: Prof. Dr. Lúcio Francelino Araújo.

1. Carcaça. 2. Melhorador de desempenho. 3. Promotor de crescimento. 4. Prebiótico. I. Título. 
UNIVERSIDADE DE SĀO PAULO

FACULDADE DE MEDICINA VETERINÁRIA E ZOOTECNIA

\section{Comissão de Ética no uso de animais}

\section{CERTIFICADO}

Certificamos que o Projeto intitulado "Avaliação de diferentes planos nutricionais utilizando leveduras na dieta de frangos de corte", protocolado sob o $\mathrm{n}^{\circ}$ 2260/2011, utilizando 1100 (mil e cem) frangos, sob a responsabilidade do(a) Prof. Dr. Lúcio Francelino Araújo, está de acordo com os princípios éticos de experimentação animal da "Comissão de Ética no uso de animais" da Faculdade de Medicina Veterinária e Zootecnia da Universidade de São Paulo e foi aprovado em reunião de 17/8/2011.

We certify that the Research "Evaluation of different plans using nutritional yeast in the diet of broilers", protocol number 2260/2011, utilizing 1100 (one thousand and one hundred) broilers, under the responsibility Prof. Dr. Lúcio Francelino Araújo, agree with Ethical Principles in Animal Research adopted by "Ethic Committee in the use of animals" of the School of Veterinary Medicine and Animal Science of University of São Paulo and was approved in the meeting of day $8 / 17 / 2011$.

São Paulo, 18 de agosto de 2011.

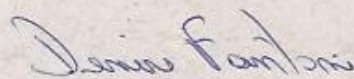

Profa. Dra. Denise Tabacchi Fantoni

Presidente 


\section{FOLHA DE AVALIAÇÃO}

Nome: VALADARES, Lara Santa Cruz

Título: Avaliação de diferentes planos nutricionais utilizando leveduras na dieta de frangos de corte

Dissertação apresentada ao

Programa de Pós-Graduação em

Nutrição e Produção Animal da

Faculdade de Medicina Veterinária

e Zootecnia da Universidade de São

Paulo para obtenção do título de

mestre em Ciências

Data em:

\section{Banca Examinadora}

Prof. Dr.

Instituição:

Julgamento:

Prof. Dr.

Instituição:

Julgamento:

Prof. Dr.

Instituição:

Julgamento: 
Como foi dito por Fernando Pessoa, “O homem é do tamanho do seu sonho".

Por este motivo dedico esta realização a minha mãe e minha filha, Sofia por termos embarcado juntas neste sonho. 


\section{AGRADECIMENTOS}

A uma força superior que sempre me acompanha e ilumina meus caminhos.

Ao professor Dr. Lúcio Francelino Araujo e a professora Dra. Cristiane Araújo pela paciência, calma, amizade e orientação nestes anos de convivência.

A Agropecuária Serrote Redondo pelo apoio e suporte durante esse período de retorno a universidade.

A minha mãe e minha filha, por me acompanharem por toda parte nesta longa caminhada.

As minhas queridas amigas Laura, Maria e Polyana por terem me incentivado e apoiado na hora de decidir e enfrentar os problemas dessa jornada.

Ao VNP- Departamento de Nutrição e Produção Animal, e a todos que fazem parte dele.

A empresa ICC pelo financiamento do projeto.

A todos os colegas de universidade, em especial João, Caio, Roberta, Natália, Cláudia, Monique, Bárbara, Vanussa, Lívea e Teresa.

Aos meus queridos amigos da Republica Ressaca, por me ajudarem no momento de adaptação e me acolherem em casa.

Ao meu irmão, Augusto Valadares por toda a ajuda quando precisei e minhas queridas primas Bel e Dani.

A amiga Mariana Almeida por sempre estar presente e a minha querida e não tão presente Catarina.

Por fim a mina querida tia Graças Valadares que de onde estiver acredito que compartilha essa alegria e guia meus passos. 


\section{RESUMO}

VALADARES, L. S. C. Avaliação de diferentes planos nutricionais utilizando leveduras na dieta de frangos de corte. [Evaluation of different nutritional plans using yeast in the diet of broilers]. 2012. 39 f. Dissertação (Mestrado em Ciências) - Faculdade de Medicina Veterinária e Zootecnia, Universidade de São Paulo, São Paulo, 2012.

O objetivo desse experimento foi verificar diferentes planos nutricionais através da utilização de diferentes tipos de levedura na alimentação de frangos de corte no período de 1 a 42 dias. Foram utilizadas leveduras autolizada, hidrolizada e levedura íntegra e sua influência sobre parâmetros de desempenho (ganho de peso, consumo de ração e conversão alimentar) e características de carcaça (rendimento de carcaça, rendimento de peito e rendimento de pernas). Foram utilizados 1.080 pintinhos de corte, machos de um dia de idade, da linhagem Cobb, distribuídos em delineamento experimental inteiramente casualizado, em esquema fatorial 3 x 3: 3 formas de suplementação de levedura no período de 1 a 14 dias (sem levedura, levedura autolisada e levedura hidrolisada) e 3 formas de suplementação no período de 15 a 42 dias (sem suplementação, levedura autolisada e levedura íntegra) mais um tratamento controle positivo, com a adição de um antibiótico promotor de crescimento (APC), totalizando 10 tratamentos, 9 repetições e 12 aves por unidade experimental. As dietas utilizadas foram formuladas a base de milho e farelo de soja, sendo utilizado como APC a bacitracina de zinco na inclusão de $0,5 \mathrm{~kg} /$ ton em todas as dietas. No período de 1 a 14 dias foi utilizado o nível de inclusão de $10 \mathrm{~kg} /$ ton das leveduras autolisada e hidrolisada e no período de 15 a 42 dias, 5kg/ton das leveduras autolisada e íntegra. As análises estatísticas dos dados foram realizadas pelo método da análise de variância com o auxílio do procedimento GLM do SAS (2002) e em caso de significância estatística, as médias foram comparadas pelo teste de Tukey, no nível de 5\% de probabilidade. No período de 1 a 14 dias a levedura hidrolisada apresentou melhor viabilidade de uso na dieta. Para a utilização de um programa contínuo, a combinação do uso da levedura hidrolisada no período de 1 a 14 dias e de levedura autolizada no período de 15 a 42 dias, apresenta-se como melhor resposta pelas aves.

Palavras-chave: Avicultura. Carcaça. Melhorador de desempenho. Promotor de crescimento. Prebiótico. 


\begin{abstract}
VALADARES, L. S. C. Evaluation of different nutritional plans using yeast in the diet of broilers. [Avaliação de diferentes planos nutricionais utilizando leveduras na dieta de frangos de corte]. 2012. 39 f. Dissertação (Mestrado em Ciências) - Faculdade de Medicina Veterinária e Zootecnia, Universidade de São Paulo, São Paulo, 2012.
\end{abstract}

The objective of this experiment was to evaluate different nutritional plans using various types of yeasts in broiler chicken feed during a 42-day period. We used autolyzed, hydrolyzed, and whole yeasts and evaluated their influence on performance parameters (weight gain, feed intake, and food conversion) and carcass features (whole chicken yield, breast yield, and leg yield). A total of 1080 1-day-old male Cobb lineage chicks were used and distributed across a completely randomized $3 \times 3$ factorial experimental design. The treatments were comprised of 3 yeast supplement types during days 1 to 14 (i.e., without yeast, autolyzed yeast, and hydrolyzed yeast), 3 supplement types during days 15 to 42 (as above), and growth-promoting antibiotic (GPA) as positive control for a total of 10 treatments, 9 replications, and 12 birds per experimental unit. The diets were formulated based on corn and soybean meal, and $0.5 \mathrm{Kg} /$ ton of zinc bacitracin was included as the GPA in the control diets. We used $10 \mathrm{Kg} /$ ton of autolyzed and hydrolyzed yeast in days 1 to 14 , and $5 \mathrm{Kg} /$ ton of autolyzed and whole yeast during days 15 to 42 . Statistical data analyses were conducted using an analysis of variance and the SAS GLM procedure (2002), and statistically significant means were compared using Tukey's test at the 5\% probability level. In days 1 14 , the hydrolyzed yeast presented the best viability of use in the chicken diet. As an ongoing program, the birds responded best to the combination of hydrolyzed yeast in days 1 to 14 and autolyzed yeast in days 15 to 42 .

Keywords: Poultry. Housing. Performance enhancer. Growth promoter. probiotic 


\section{LISTA DE FIGURAS}

\section{CAPÍTULO I}

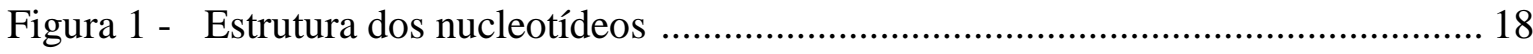

Figura 2 - Digestão e absorção dos nucleotídeos ............................................................ 20 


\section{LISTA DE TABELAS}

\section{CAPÍtULO I}

Tabela 1 - Concentração de nucleotídeos nos alimentos

\section{CAPÍTULO II}

Tabela 2 - Composição das dietas experimentais

Tabela 3 - Desempenho de frangos de corte alimentados com diferentes programas nutricionais no período de 1 a 14 dias

Tabela 4 - Desempenho de frangos de corte alimentados com diferentes programas nutricionais no período de 15 a 42 dias

Tabela 5 - Desempenho de frangos de corte alimentados com diferentes programas nutricionais no período de 1 a 42 dias

Tabela 6 - Características de carcaça de frangos de corte alimentados com diferentes programas nutricionais no período de 1 a 42 dias 


\section{SUMÁRIO}

\section{CAPítULO I}

1 INTRODUÇÃO

2 REVISÃO DE LITERATURA …...................................................................... 17

3 OBJETIVOS E HIPÓTESE.......................................................................................... 23

CAPÍTULO II - AVALIAÇÃO DE DIFERENTES PLANOS NUTRICIONAIS UTILIZANDO LEVEDURAS NA DIETA DE FRANGOS DE CORTE

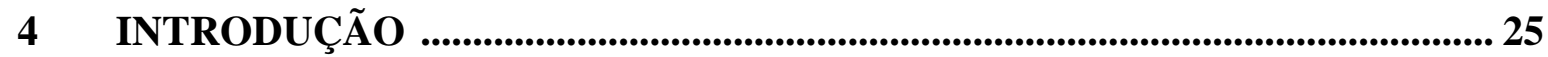

5 MATERIAL E MÉTODOS …........................................................................... 27

$6 \quad$ RESULTADOS E DISCUSSÃO ........................................................................... 30

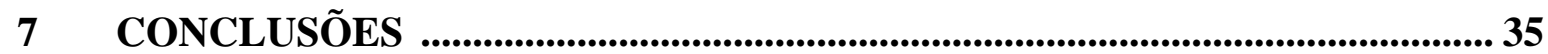

REFERÊNCIAS .................................................................................................. 36 
CAPÍTULO I 


\section{INTRODUÇÃO}

A população mundial chegou a 7 bilhões de pessoas em 2011, e existe uma forte tendência de países em desenvolvimento consumirem cada vez mais proteína de origem animal. Os consumidores atuais tem melhor definido o conceito de qualidade e são mais exigentes em relação ao que consomem e como esses alimentos são produzidos.

Os governos cada vez mais restringem a utilização de antibióticos como melhoradores de desempenho na nutrição animal, como foi o caso da união europeia em 2006. Com essa realidade e previsão de futuro compete ao profissional de produção animal uma grande responsabilidade e desafio para o desenvolvimento de técnicas que acompanhem essas tendências. Neste caso a utilização de levedura tem papel de grande importância para o desenvolvimento da produção de proteína animal para atender o mercado atual.

A visão mais atualizada na produção está ligada a prevenção e o conceito da utilização de pré-bióticos, pró-bióticos e simbióticos é bastante oportuno neste cenário. Novas fontes de nutrientes têm sido buscadas para vencer desafios como a saúde intestinal, a melhora da digestibilidade e do sistema imune. Desta forma, aditivos alternativos têm sido pesquisados, dentre eles as leveduras, em suas diversas formas de aplicação e cujos benefícios da sua utilização merecem ser ressaltados.

Ao final dos anos 70, a criação do Programa Nacional do Álcool (Proálcool) estimulou o desenvolvimento da produção de álcool em larga escala, alavancando o beneficiamento do creme de leveduras, como um de seus principais subprodutos. Na década de 70 e 80 , diversos trabalhos zootécnicos foram realizados, porém, tendo como único objetivo viabilizar a levedura como uma fonte protéica alternativa sendo que até o início da década de 90, seu uso na alimentação animal foi em função de sua composição nutricional.

Nos últimos anos o uso de leveduras se tornou cada vez mais frequente, devido suas características nutricionais como a presença de enzimas, nucleotídeos e metabólitos de fermentação, que são de fundamental importância na melhora da performance animal.

Com a proibição do uso de ingredientes de origem animal na dieta das aves, as formulações passaram a ser feitas somente com ingredientes de origem vegetal. Contudo, estas dietas tornaram-se ricas em potássio o que tem gerado alguns problemas entéricos. A 
levedura, através de sua ação promotora da saúde intestinal pode viabilizar a utilização destas dietas, diminuindo a probabilidade de aparecimento de diarréias e, consequentemente, melhorando o desempenho dos animais.

Sob o ponto de vista industrial, as leveduras são muito interessantes, pelo fato de essa matéria-prima ser composta de uma variedade de componentes úteis e, por esse motivo, amplamente explorada. O aproveitamento da biomassa da levedura pode ser feito integralmente (ativa e inativa), ou apenas alguns dos seus componentes, produtos derivados da parede celular e também do conteúdo celular.

As leveduras são fungos unicelulares cosmopolitas, sendo amplamente distribuídas no solo, superfícies de folhas, frutos e no trato gastrointestinal dos animais. São as mais antigas fontes unicelulares de proteínas consumidas pelo homem por meio de produtos naturais, bebidas e alimentos elaborados por processos fermentativos.

A origem da levedura utilizada na nutrição animal se dá principalmente em destilarias de álcool (etanol) e nas cervejarias onde são gerados excedentes de células de levedura que, inativadas termicamente ou não, poderão ser usadas diretamente (células íntegras de levedura) ou ser processadas para obtenção de vários derivados como o autolisado e o extrato de levedura, que vêm sendo utilizados na formulação de produtos para humanos e animais, em forma de complementos nutritivos, flavorizantes, entre outras aplicações.

As leveduras, sejam elas vivas ou não, possuem em sua composição uma fração de carboidratos (20\% a 40\%), que na grande maioria fazem parte da parede celular, que é composta principalmente por glucanas e mananas (MOS), os quais há uma hipótese que tem impacto no sistema imunológico e habilidade em prevenir a colonização de bactérias patogênicas no trato gastrointestinal. Outro componente importante são os nucleotídeos. Os nucleotídeos, desde que disponíveis, podem ter efeito sobre o trato gastrointestinal, aumentando o crescimento e influenciando positivamente a flora bacteriana dos animais. Para que os nucleotídeos presentes nas leveduras se tornem disponíveis se faz necessário um tratamento enzimático que consiste de autólise, aonde a própria levedura é induzida a produzir enzimas com o intuito de rompimento da membrana celular e posterior hidrólise onde ocorre a adição de enzimas exógenas (proteases e nucleases), na qual se objetiva disponibilizar ao máximo o conteúdo citoplasmático. 
A levedura inativa integra é sangrada do processo fermentativo, inativada e seca diretamente no spray dried.

A levedura autolisada é obtida após a sangria do processo fermentativo a levedura ainda viva é colocada em uma dorna especifica onde através de alterações de temperatura e pH cria-se uma condição desfavorável para a mesma que devido a este estrese começa a produzir enzimas endógenas que romperão membrana celular e com isso ocorre uma melhora na digestibilidade.

A levedura hidrolisada vem do mesmo processo da levedura autolisada, porém após a autólise é feita uma adição de enzimas exógenas (proteases e nucleases) para quebrar os polipeptideos em peptideos e nucleotideos em nucleosideos. 


\section{REVISÃO DE LITERATURA}

O extrato de leveduras possui aproximadamente $40 \%$ de aminoácidos livres, 5 a $7 \%$ de nucleotídeos, além de peptídeos, vitaminas e minerais segundo Rutz et al. (2005).

Generoso et al. (2008) ao analisar a EMA em levedura de cana com $40 \%$ e $43 \%$ de PB utilizando frangos de corte machos na idade de 21 a 30 dias e 40 a 50 dias achou os seguintes valores de EMA: levedura $40 \%$ de $\mathrm{PB} 1^{\circ}$ período $2395 \mathrm{~kg} / \mathrm{kg}$ matéria natural e $2^{\circ}$ período $2483 \mathrm{~kg} / \mathrm{kg}$ de matéria natural e levedura 43\% PB $1^{\circ}$ período $2626 \mathrm{~kg} / \mathrm{kg}$ matéria natural e $2^{\circ}$ período $2726 \mathrm{~kg} / \mathrm{kg}$ de matéria natural.

Diversos trabalhos mostram a utilização e eficiência da levedura em nutrição animal, Silva e Silva et al. (2009) encontrou maior consumo de ração em dietas contendo extrato de leveduras associada a prebiótico na fase de 1 a 7 dias e na fase de 1 a 21 dias o autor encontrou uma melhora na conversão no programa alimentar que utilizou extrato de levedura no período pré-inicial. Este resultado está de acordo com o encontrado por Zhang et al. (2005), que aos 21 dias de idade encontrou melhor resultado de conversão alimentar utilizando parede e extrato de levedura e pior utilizando levedura integra.

Os nucleotídeos são os constituintes do DNA e RNA que estão presentes em todo o organismo animal e participam de diversos processos relacionado ao seu desenvolvimento. Os nucleotídeos são moléculas com uma grande diversidade estrutural, sua estrutura consiste em uma base nitrogenada, essa base nitrogenada pode ser uma purina ou pirimidina e está ligada a um açúcar, uma pentose. O DNA está ligado a uma desoxirribose e o RNA a uma ribose. Esta pentose está ligada a um grupo fosfato através de seu grupo hidroxila. Na figura 1 temos a ilustração dessa molécula 
Figura 1 - Estrutura dos nucleotídeos

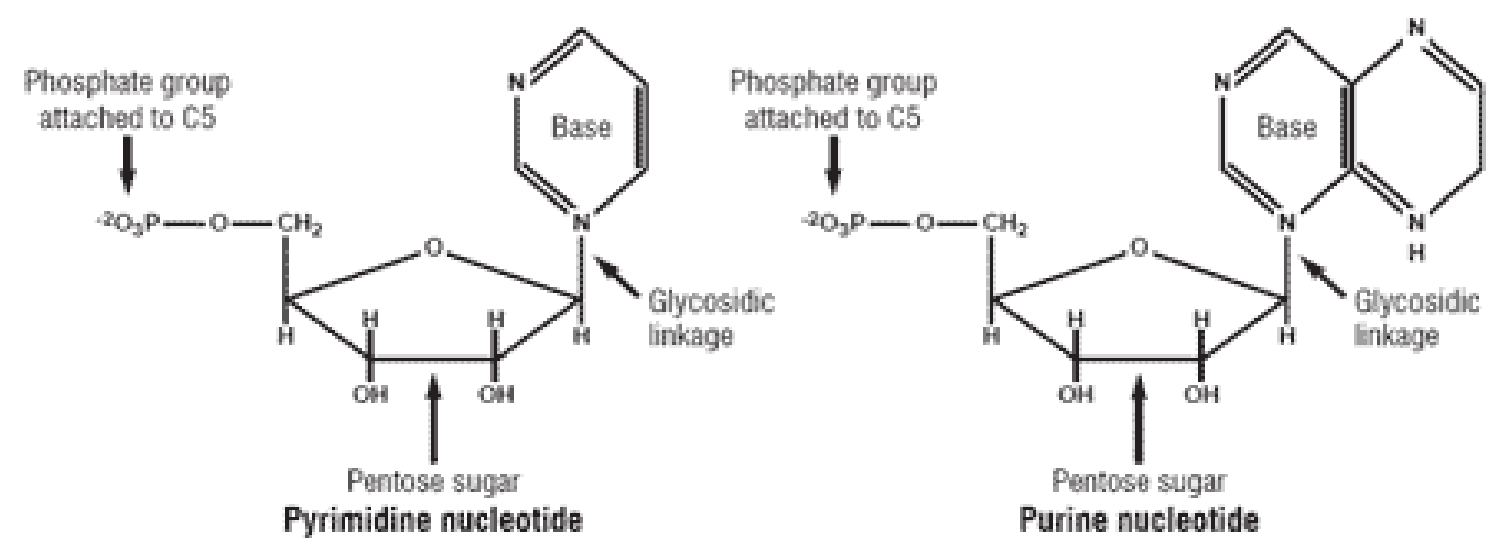

Segundo Voet e Voet (1995), os nucleosídeos não tem o grupo fosfato apenas uma base nitrogenada ligada a um açucar através de uma ligação glicosídea. Os ácidos nucleicos são cadeias de nucleotídeos ligados entre si e os mesmos conjugados a proteínas formam as nucleoproteínas.

Alimentos ricos em proteínas são fontes de nucleotídeos segundo Carver e Walker (1995). Alimentos que possuem elementos celulares são potenciais fontes de nucleotídeos em formada de nucleoproteínas, como é o caso da levedura que sofre um processo de quebra de parede celular para a liberação de todo o seu conteúdo celular.

Fontes de proteína de levedura de panificação ou levedura de cerveja e extrato de levedura, são ingredientes que têm uma concentração relativamente elevada de nucleotídeos (MALONEY, 1998; INGLEDEW, 1999; TIBBETS, 2002). Usualmente os ingredientes não são analisados para a determinação de nucleotídeos, mas temos alguns dados disponiveis e os mesmos mostram que os ingredientes mais utilizados tem uma quantidade relativamente baixa de nucleotídeos (Tabela 1). 
Tabela 1- Concentração de nucleotídeos nos alimentos

\begin{tabular}{llllll}
\hline & \multicolumn{5}{c}{ Nucleotideo (mg/g) } \\
Ingredientes & 5' CMP & 5' AMP & 5' GMP & 5' UMP & 5' IMP \\
\hline Cevada & 0.002 & 0.001 & 0.001 & 0.000 & 0.001 \\
Caseína & 0.001 & 0.000 & 0.000 & 0.000 & 0.000 \\
Milho & 0.003 & 0.002 & 0.003 & 0.000 & 0.001 \\
Farinha de Peixe & 0.026 & 0.011 & 0.002 & 0.001 & 0.035 \\
Aveia & 0.003 & 0.003 & 0.003 & 0.001 & 0.001 \\
$\begin{array}{l}\text { Plasma Prot. Spray dried } \\
\text { Células Vermelhas spray }\end{array}$ & 0.002 & 0.002 & 0.002 & 0.000 & 0.001 \\
dried & 0.000 & 0.044 & 0.003 & 0.002 & 0.006 \\
$\begin{array}{l}\text { Proteína de Soja } \\
\text { concentrada }\end{array}$ & 0.000 & 0.001 & 0.002 & 0.000 & 0.001 \\
Farelo de Soja 44\% & 0.016 & 0.008 & 0.003 & 0.009 & 0.002 \\
& & & & & \\
\hline
\end{tabular}

Fonte: Mateo et al. (2004).

Segundo Tibbetts (2002) o leite materno, potencialmente nas primeiras semanas, possui uma quantidade de nucleotídeos com grande variação. Essa variação justificaria a suplementação desse nutriente. Aliado a isso, ainda segundo o autor em momentos de rápido crescimento e estresse a requisição por nucleotídeos aumenta, porém são informações que precisam de mais dados científicos na nutrição animal. Se nos concentramos nos dados de Tibbetts (2002) e usamos os dados de Mateo et al. (2004) em relação a tabelada de nucleotídeos em matérias primas e estudo em que o mesmo comprovou a flutuação nas primeiras semanas de vida na quantidade de nucleotídeos em leite de uma fêmea sunía podemos justificar as diferenças encontradas em experimentos utilizando leveduras nas primeiras semanas e em culturas que tem altas taxas de crescimento e são expostas a estresse ambientas com é o caso da avicultura.

Nucleoproteínas dietética, ácidos nucléicos e nucleotídeos precisam ser hidrolisados enzimaticamente antes da absorção, porque só nucleosídeos, bases, e pequenas quantidades de nucleotídeos são absorvidos. Este processo ocorre no intestino delgado. Endonucleases, fosfodiesterases e fosforilase de nucleosídeos são as principais enzimas envolvidas nesse processo, como mostra a figura 2. 
Figura 2 - Digestão e Absorção dos nucleotídeos

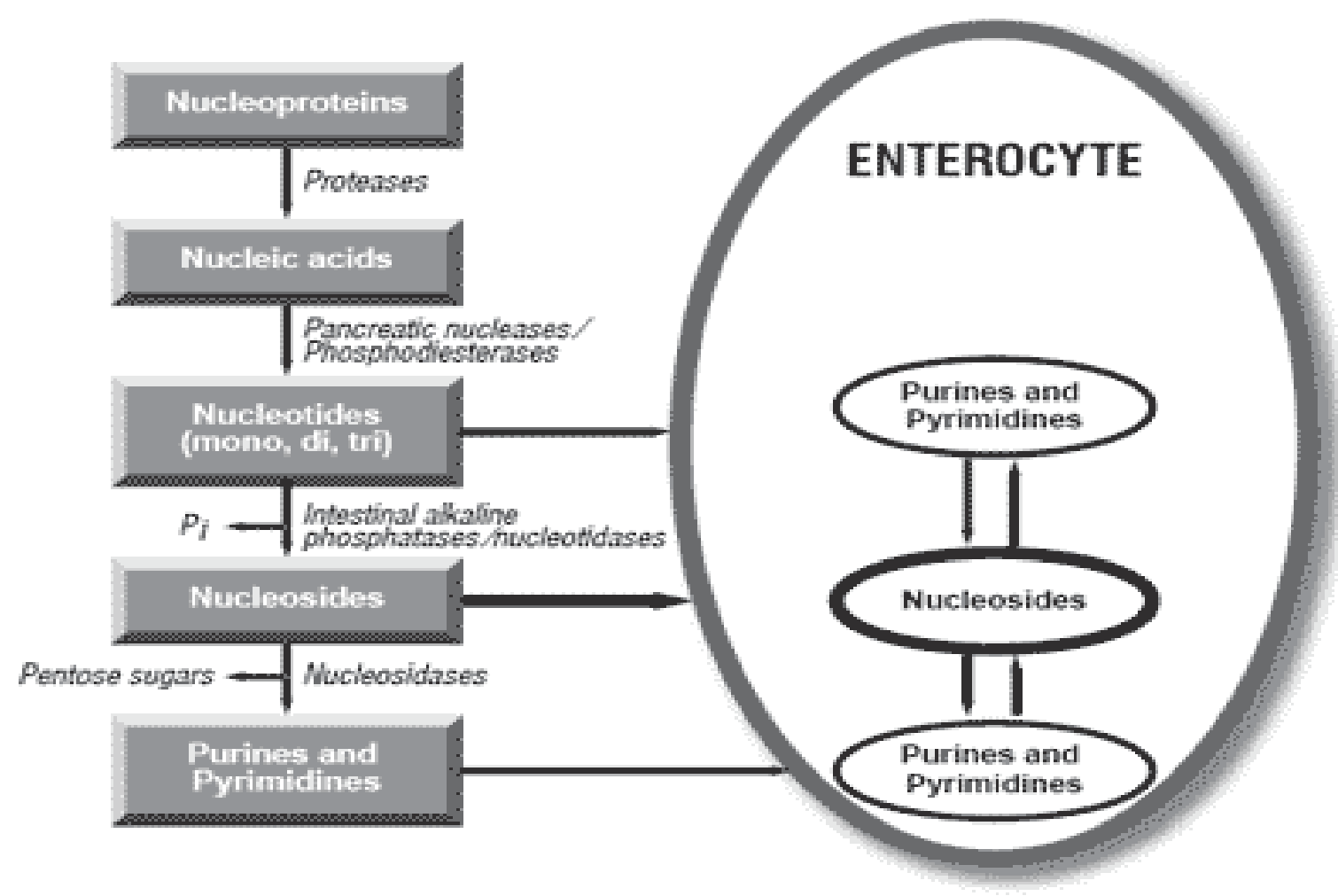

Fonte: Uauy (1991).

O duodeno tem a maior capacidade de absorção segundo Bronk e Hastewell (1987). Diferenças na eficiência de absorção entre os nucleosídeos foram relatado com guanosina sendo retomado mais rapidamente e em condições fisiológicas, nucleotídeos têm uma capacidade limitada para passar através das membranas celulares segundo Sanderson e Ele, (1994). Isto pode ser devido à ausência de um sistema de transporte de nucleotídeos. Nucleotídeos também têm um grupo fosfato de alta carga negativa que impede a absorção. Portanto, a forma de nucleosídeos é o principal veículo para a entrada de purinas e pirimidinas nas células epiteliais. Mais de $90 \%$ de nucleosídeos dietéticos e endógenos e bases são absorvidos pelo enterócito segundo Salati et al. (1984) e Uauy (1989).

O transporte de nucleosídeos no enterócito ocorre por difusão facilitada e por $\mathrm{Na}+-$ dependente específicos mecanismos transportadora mediados segundo Bronk e Hastewell (1987).

Os nucleotídeos estão en constante processo de sintese e catabolismo. Os nucleotideos podem ser sintetizados no citosol dos hepatocitos(síntese do novo), o que leva a um alto custo 
metabolico na forma de energia ATP, ou resgatados da alimentação onde haverá uma economina de energia e permitem que as células (ou seja, leucócitos, hemácias, células da medula óssea, células da mucosa intestinal e linfócitos), que são incapazes de síntese de novo, manter suas reservas de nucleotídeos segundo Sanderson e He (1994).

Os nucleotideos são fontes de energia, e participam da regeneração de tecidos a sua suplementação na dieta tem sido associada com imunidade tanto humoral e celular, mas o mecanismo exato ainda não foi elucidado. Privação de nucleotídeos causou a prisão de células $\mathrm{T}$ na fase $\mathrm{G}$ do ciclo celular, impedindo uma resposta a vários sinais imunológicos que ocorrem pela transição para a fase S segundo Kulkarni et al. (1994). Oliver et al. (2003) ao suplementar bezerros recém desmamados com nucleotideos puros teve um maior nível de IgG comparado aos do grupo controle. Apesar de todas as hipoteses ligadas a nucleotideos e imunidade estes mecanismos precisam se melhor elucidados na nutrição animal.

Ferreira et al. (2009) ao analisar o nivel de inclusão crescente $(0,1,2,34 \mathrm{~kg}$ de parede de levedura/tonelada de ração) sobre o peso de orgão linfoides, resposta imune e perfil hematologico de progenie de matrizes reprodutoras de 34 e 54 semanas da linhagem Coob encontrou que nos frangos provenientes das matrizes de 57 semanas com suplementação de 3 kg de parede de levedura a reação inflamatória foi mais intensa comparada ao controle e na progenie de matrizes de 34 semanas com 28 dias de idade e suplementação de $1 \mathrm{~kg}$ de parede de levedura houve um aumento absoluto da bolsa cloacal comparada ao controle. O peso do timo e barço não foi afetado pelo estudo e o autor não conprovou os resultados de parede de levedura sobre os paramentros imunologicos de frangos de corte.

Sucuripa et al. (2007) ao realizar um experimento com codornas japonesas de postura e com a inclusão de $0,3 \%, 6 \%, 9 \%, 12 \%$ e $15 \%$ de levedura de cana-de-açucar notou que com o acrescimo de levedura nas rações houve um aumento no consumo, aumento no peso do ovo e piora na conversão alimentar. O autor recomendou um nível maximo de $11 \%$ de inclusão para codornas porem os tratamentos não afetaram a postura e massa dos ovos.

Butolo (1991) não recomenda o inclusão de mais de 10\% de levedura nas rações para aves, pois teremos um menor desenpenho zootécnico devido a baixa digestibilidade da parede celular da levedura.

Silva e Amoroso et al. (2009) utilizou frangos de corte alojados em gaiolas metabólicas com o método de coleta total de fezes e galos cecectomizados para a 
determinação da composição do extrato de leveduras.Os aminoácidos em maior proporção no extrato de leveduras foram: ácido glutâmico, leucina, ácido aspártico, alanina, prolina, lisina, valina, serina, isoleucina, glicina e treonina. Os coeficientes de digestibilidade foram: $65,79 \%$ da matéria seca, $65,47 \%$ da proteína bruta e 99,42\% dos amonoácidos em frangos de corte.

Moreira et al. (1998) ao utilizar levedura desidratada por spray-dry para suínos em crescimento e terminação constatou que ate uma inclusão de $7 \%$ a levedura pode proporcionar desempenho e características de carcaça semelhantes ao de animais alimentados com levedura contendo milho e farelo de soja. $\mathrm{O}$ autor contatou que a suplementação de levedura não teve efeito sobre o consumo diário de ração porém teve um efeito linear negativo sobre o ganho de peso diário nas fases de crescimento e terminação, o autor também constatou uma diminuição na conversão alimentar na fase de crescimento.

Machado et al. (2010) ao realizar um experimento com frangos de corte utilizando 3\% de levedura de cana spray dryer, 3\% de levedura autolizada, 0,3\% de parede celular de levedura e antibiótico promotor de crescimento (bacitracina de zinco) não encontrou diferença de desempenho zootécnico entre os tratamentos no período de 1 a 21 dias, porem no período total da criação os tratamentos de melhor resultado foram os que utilizaram antibiótico como promotor de crescimento, parede celular de levedura e a levedura autolisada.

Nunes et al. (2008) ao utilizar níveis crescentes de extrato de levedura $(0 ; 1 \% ; 2 \%$ e $3 \%$ ) constatou que esses níveis não afetaram o desempenho produtivo de galinhas poedeiras com 47 a 75 semanas de idade e com uma ração a base de milho e soja. 


\section{OBJETIVOS E HIPÓTESE}

O objetivo deste trabalho foi avaliar a melhor forma de suplementação de levedura para a avicultura através da criação de um plano de suplementação englobando todas as fases de criação, podendo assim encontrar a melhor maneira de utilização desse ingrediente. Apesar de vários trabalhos comprovarem a eficiência da utilização de levedura para frangos de corte poucos estabelecem a melhor maneira de utiliza-las.

A hipótese é de que a suplementação continua de levedura por todas as fases de criação terá o melhor resultado zootécnico. 
CAPÍtUlO II - AVALIAÇÃO DE DIFERENTES PLANOS NUTRICIONAIS UTILIZANDO LEVEDURAS NA DIETA DE FRANGOS DE CORTE. 


\section{INTRODUÇÃO}

Ao final dos anos 70, a criação do Proálcool levou a um aumento no beneficiamento do creme de leveduras, subproduto da fermentação alcoólica, que foi usado na alimentação animal como fonte protéica alternativa.

Nos últimos anos o uso de leveduras se tornou cada vez mais frequente, devido suas características nutricionais como a presença de enzimas, nucleotídeos e metabólicos de fermentação, que são de fundamental importância na melhora da performance animal.

Com a proibição do uso de ingredientes de origem animal na dieta das aves, pela Comunidade Européia, as formulações passaram a ser feitas somente com ingredientes de origem vegetal. Contudo, estas dietas tornaram-se ricas em potássio o que tem gerado alguns problemas entéricos. A levedura, através de sua ação promotora da saúde intestinal pode viabilizar a utilização destas dietas.

O aproveitamento da biomassa da levedura pode ser feito integralmente (ativa e inativa), ou apenas alguns dos seus componentes, produtos derivados da parede celular e também do conteúdo celular.

$\mathrm{Na}$ forma inativa as leveduras são retiradas do processo fermentativo, inativadas e sofrem secagem pelo método de spray dried. O teor de proteína bruta variando de $30,77 \%$ a $56 \%$, alta concentração de vitaminas do complexo B e um bom perfil aminoacídico, são ricas em lisina e treonina, o que permite a combinação com os cereais. É também um ingrediente altamente palatável e com ação profilática, contribuindo para a redução de condições de estresse nos animais.

A levedura autolisada é preparada por indução de autodigestão ou rompimento mecânico (ASSIS, 1996) e consiste no conteúdo total da célula lisada, incluindo os componentes hidrossolúveis, as proteínas solúveis e a parede celular. 
A levedura hidrolisada sofre o mesmo processo da levedura autolisada, porém após a autólise é feita uma adição de enzimas exógenas (proteases e nucleases) para quebrar os polipeptideos em peptideos e nucleotideos em nucleosideos.

Apesar da diversidade de produtos existentes, com suas diferentes características, não existem estudos demonstrando se há algum programa de alimentação ideal para o uso destas leveduras na dieta de frangos de corte.

O objetivo deste trabalho foi avaliar o uso de programas nutricionais, com base nos diferentes tipos de leveduras, para frangos de corte no período de 1 a 42 dias de idade. 


\section{MATERIAL E MÉTODOS}

Este trabalho foi realizado no aviário experimental da Faculdade de Zootecnia e Engenharia de Alimentos da Universidade de São Paulo, em Pirassununga - SP, avaliando o uso de programas nutricionais, com diferentes tipos de leveduras para frangos de corte no período de 1 a 42 dias de idade.

Foram utilizados 1.080 pintinhos de corte, machos de um dia de idade, da linhagem Cobb, distribuídos em delineamento experimental inteiramente casualizado, em esquema fatorial 3 x 3: 3 formas de suplementação de levedura no período de 1 a 14 dias (sem levedura, levedura autolisada e levedura hidrolisada) e 3 formas de suplementação no período de 15 a 42 dias (sem suplementação, levedura autolisada e levedura íntegra) mais um tratamento controle positivo, com a adição de um antibiótico promotor de crescimento (APC), totalizando 10 tratamentos, 9 repetições e 12 aves por unidade experimental. Como APC foi utilizado a bacitracina de zinco na inclusão de $0,5 \mathrm{~kg} /$ ton em todas as dietas. No período de 1 a 14 dias foi utilizado o nível de inclusão de $10 \mathrm{~kg} /$ ton das leveduras autolisada e hidrolisada e no período de 15 a 42 dias, $5 \mathrm{~kg} /$ ton das leveduras autolisada e íntegra. Nos tratamentos aonde foram avaliadas as leveduras, não foi utilizado APC. Em todas as dietas foi utilizado um ionóforo (nicarbazina + narasina) como agente coccidiostático.

As dietas experimentais foram formuladas a base de milho e farelo de soja de forma a atender as exigências nutricionais das aves nas respectivas fases de criação e foram fornecidas utilizando os seguintes períodos: inicial ( 1 a 14 dias), crescimento (15 a 26 dias), final (27 a 35 dias) e de retirada (36 a 42 dias), sendo descritas na tabela 2. As dietas experimentais foram obtidas através da substituição do inerte pela respectiva levedura.

As aves foram alojadas em um galpão com dimensões de 45 x 10 m, cumeeira com orientação leste-oeste, pé-direito de $2,5 \mathrm{~m}$ coberto com telhas de fibrocimento, contendo boxes de 1,00 x 1,10 m cada. As aves foram vacinadas contra as doenças de Marek, Newcastle e Gumboro no incubatório.

A cama utilizada para a criação das aves foi de maravalha e proveniente de material utilizado na criação de outros lotes, sendo que essa cama não recebeu nenhum tratamento para a sua reutilização, com o objetivo de se aproximar dos desafios encontrados a campo. Com 
esse mesmo objetivo as instalações e comedouros não foram higiênizados e não houve vazio sanitário no galpão. As aves receberam água e alimentação à vontade. Os boxes foram equipados com comedouros tubulares e bebedouros tipo nipple.

Tabela 2 - Composição das dietas experimentais

\begin{tabular}{|c|c|c|c|c|}
\hline & Inicial & Crescimento & Final & Retirada \\
\hline Milho & 53,927 & 58,720 & 64,758 & 68,333 \\
\hline Farelo de Soja & 36,442 & 32,163 & 26,434 & 23,437 \\
\hline Óleo de Frango & 3,662 & 4,648 & 4,493 & 4,146 \\
\hline Fosfato Bicálcico & 2,095 & 1,845 & 1,716 & 1,462 \\
\hline Calcário & 0,905 & 0,838 & 0,834 & 0,786 \\
\hline Sal & 0,461 & 0,429 & 0,435 & 0,437 \\
\hline Metionina & 0,392 & 0,201 & 0,206 & 0,208 \\
\hline Lisina & 0,428 & 0,150 & 0,218 & 0,255 \\
\hline Treonina & 0,183 & 0,003 & 0,051 & 0,081 \\
\hline VIT/MIN & 0,400 & 0,400 & 0,250 & 0,250 \\
\hline Ionóforo & 0,055 & 0,055 & 0,055 & 0,055 \\
\hline Bacitracina de $\mathrm{Zn}$ & 0,050 & 0,050 & 0,050 & 0,050 \\
\hline Levedura & 0,000 & 0,000 & 0,000 & 0,000 \\
\hline Inerte & 1,000 & 0,500 & 0,500 & 0,500 \\
\hline \multirow[t]{2}{*}{ Total } & 100,00 & 100,00 & 100,00 & 100,00 \\
\hline & \multicolumn{4}{|c|}{ Níveis Nutricionais } \\
\hline $\mathrm{EM}(\mathrm{kcal} / \mathrm{kg})$ & 3.042 & 3.141 & 3.196 & 3.218 \\
\hline $\mathrm{PB}(\%)$ & 22,00 & 20,00 & 18,00 & 17,00 \\
\hline $\mathrm{Ca}(\%)$ & 1,00 & 0,90 & 0,85 & 0,76 \\
\hline $\operatorname{Pd}(\%)$ & 0,50 & 0,45 & 0,42 & 0,37 \\
\hline Metionina $\operatorname{dig}(\%)$ & 0,46 & 0,41 & 0,38 & 0,37 \\
\hline Lisina $\operatorname{dig}(\%)$ & 1,21 & 1,05 & 0,97 & 0,93 \\
\hline Treonina $\operatorname{dig}(\%)$ & 0,77 & 0,67 & 0,64 & 0,63 \\
\hline
\end{tabular}

O sistema de criação foi o de ambiente controlado, sendo que o aquecimento foi feito através de um sistema automático a gás que era acionado de acordo com a necessidade de temperatura dos animais até os 14 dias de criação. Após este período, a temperatura foi controlada através de um painel de controle o qual determinava o acionamento de exaustores 
e nebulizadores para proporcionar o conforto térmico das aves. O programa de luz adotado foi o de 24 horas de iluminação em todas as fases de criação sendo que o galpão era completamente fechado.

Foram avaliados dados de desempenho (consumo, ganho de peso e conversão alimentar) nos períodos de 1 a 14 dias e de 1 a 42 dias. No final do experimento, aos 42 dias, duas aves por repetição foram selecionadas e abatidas para a determinação das características de carcaça (rendimento de carcaça, peito e pernas). As aves foram abatidas, resfriadas por um período de 24 horas e posteriormente foram realizados a determinação dos cortes comerciais.

As análises estatísticas dos dados de desempenho zootécnico e rendimento de carcaça foram realizadas pelo método da análise de variância com o auxílio do procedimento GLM do SAS (2002) e em caso de significância estatística, as médias foram comparadas pelo teste de Tukey, no nível de $5 \%$ de probabilidade. 


\section{RESULTADOS E DISCUSSÃO}

Segundo Barbalho (2009) e Yonemura (2011) ao comparar dietas com níveis crescentes de levedura hidrolisada e dietas sem suplementação de promotores de crescimento, na fase inicial de frangos de corte, obtiveram resposta superior nos suplementados com levedura hidrolisada no que diz respeito a dados de desempenho zootécnico como: ganho de peso e conversão alimentar.

De 1 a 14 dias o fornecimento da dieta contendo levedura hidrolizada apresentou melhor ganho de peso e conversão alimentar, quando comparados aos demais tratamentos, sendo o ganho de peso em média, 5,7\% maior que o tratamento utilizando antibiótico promotor de crescimento $(\mathrm{p}<0,05)$, como mostra a tabela 3 . Estes resultados podem ser decorrentes da ação protetora que as leveduras promovem no trato digestório dos animais. A levedura hidrolisada, através dos seus constituintes, melhora a saúde intestinal das aves o que vai corresponder à melhor absorção dos nutrientes, o que pode ser comprovado através do melhor ganho de peso e conversão alimentar dos animais.

Tabela 3 - Desempenho de frangos de corte alimentados com diferentes programas nutricionais no período de 1 a 14 dias

\begin{tabular}{cccc}
\hline Tratamento & Consumo,g & Ganho de Peso,g & CA \\
\hline Antibiótico & 444 & $401^{\mathrm{b}}$ & $1,11^{\mathrm{b}}$ \\
Controle Negativo & 457 & $387^{\mathrm{c}}$ & $1,18^{\mathrm{c}}$ \\
Controle Negativo & 460 & $382^{\mathrm{c}}$ & $1,20^{\mathrm{c}}$ \\
Controle Negativo & 462 & $388^{\mathrm{c}}$ & $1,19^{\mathrm{c}}$ \\
Autolisada & 466 & $408^{\mathrm{b}}$ & $1,14^{\mathrm{b}}$ \\
Autolisada & 456 & $405^{\mathrm{b}}$ & $1,13^{\mathrm{b}}$ \\
Autolisada & 461 & $407^{\mathrm{b}}$ & $1,13^{\mathrm{b}}$ \\
Hidrolisada & 450 & $427^{\mathrm{a}}$ & $1,05^{\mathrm{a}}$ \\
Hidrolisada & 442 & $421^{\mathrm{a}}$ & $1,05^{\mathrm{a}}$ \\
Hidrolisada & 457 & $425^{\mathrm{a}}$ & $1,06^{\mathrm{a}}$ \\
P & 0,867 & 0,036 & 0,027 \\
\hline
\end{tabular}


Rutz et al. (2006) e Silva e Silva et al. (2009) encontraram melhor conversão alimentar com a utilização de extrato de leveduras na fase inicial. Vale salientar aqui a importância desde desempenho superior nesta fase, pois trata-se de uma fase decisiva que ira influenciar diretamente o resultado final.

Nos resultados encontrados por; Dinízio et al. (2002); Biggs e Parson (2009); Morales et al. (2009) e Machado et al. (2010) em experimentos contendo leveduras, antibióticos promotores de crescimento, probióticos e tratamento sem aditivos. Os mesmos não encontraram diferenças entre os tratamentos no período inicial de criação, o fato de não ter havido diferença entre os tratamentos estar ligado ao baixo desafio o que prejudica a comparação entre a ação dos agentes quanto submetidos a realidade de campo.

No caso de Maiorka et al. (2001), o mesmo obteve melhor ganho de peso nas dietas de frango de corte contendo Bacillus subtilus e parede de levedura, seguido do tratamento contendo antibióticos promotores de crescimento, depois parede de levedura e por fim o tratamento sem suplementação de aditivos .

No período de 1 a 14 dias, pode-se observar que o consumo de ração não foi alterado em função dos diversos tratamentos estudados, o que foi corroborado por Yonemura (2011) ao utilizar tratamentos com levedura hidrolisada com e sem suplementação de promotores de crescimento. Entretanto Rutz et al. (2006) e Silva e Silva et al. (2009) sugere que a adição de extrato de levedura aumenta o consumo de ração na fase inicial, o que deve estar ligado ao aumento da palatabilidade que a levedura propociona.

É importante observar que a dieta controle negativo e a dieta controle positivo diferiram no que diz respeito a ganho de peso e conversão alimentar $(p<0,05)$, tendo melhores resultados os animais suplementados como antibiótico e leveduras, o que sugere neste caso que houve desafio e as aves sem suplementação tiveram pior resultado que as suplementadas $(\mathrm{p}<0,05)$.

Embora as aves alimentadas com a dieta contendo levedura autolisada tenham apresentado o mesmo desempenho que as aves alimentadas com a dieta controle positivo, a sua utilização demonstra a possibilidade de substituição dos promotores de crescimento sem o comprometimento no desempenho dos animais. 
No período de 15 a 42 dias (Tabela 4), não foram observados efeitos das dietas experimentais sobre os parâmetros de desempenho avaliados. Entretanto, Ribeiro et al. (2008) ao substituir antibióticos promotores de crescimento por leveduras e manoligossacarideos chegou a conclusão de ser uma alternativa viável e econômica , com efeito sobre parâmetros de desempenho na fase final.

Tabela 4 - Desempenho de frangos de corte alimentados com diferentes programas nutricionais no período de 15 a 42 dias

\begin{tabular}{lccc}
\hline \multicolumn{1}{c}{ Tratamentos } & $\begin{array}{c}\text { Consumo } \\
(\mathrm{kg})\end{array}$ & $\begin{array}{c}\text { Ganho de } \\
\text { Peso (kg) }\end{array}$ & $\begin{array}{c}\text { Conversão } \\
\text { Alimentar }\end{array}$ \\
\hline Antibiótico & 4,493 & 2,538 & 1,77 \\
Sem levedura & 4,361 & 2,491 & 1,75 \\
Levedura Autolisada & 4,323 & 2,564 & 1,69 \\
Levedura Integra & 4,250 & 2,537 & 1,68 \\
Sem levedura & 4,261 & 2,516 & 1,69 \\
Levedura Autolisada & 4,625 & 2,564 & 1,80 \\
Levedura Integra & 4,333 & 2,556 & 1,70 \\
Sem levdura & 4,312 & 2,531 & 1,70 \\
Levedura Autolisada & 4,268 & 2,603 & 1,64 \\
Levedura Integra & 4,317 & 2.587 & 1,67 \\
\hline \multicolumn{1}{c}{ Probabilidade } & 0,824 & 0,939 & 0,801 \\
\hline
\end{tabular}

No período total de criação, 1 a 42 dias, o programa representado pelo fornecimento de levedura autolizada durante toda a fase de criação apresentou maior consumo de ração e pior conversão alimentar quando comparado aos demais tratamentos $(\mathrm{p}<0,05)$.

Observa-se também que o fornecimento da levedura hidrolizada até os 14 dias e da levedura autolizada até o período de abate apresentou melhor resultado de desempenho para os animais $(\mathrm{p}<0,05)$, e que a utilização de levedura hidrolizada ate 14 dias e levedura integra ate o abate também teve resultados de conversão e ganho de peso superiores $(\mathrm{p}<0,05)$, como mostra a tabela 5 . 
Tabela 5 - Desempenho de frangos de corte alimentados com diferentes programas nutricionais no período de 1 a 42 dias

\begin{tabular}{lccc}
\hline \multicolumn{1}{c}{ Tratamentos } & $\begin{array}{c}\text { Consumo } \\
(\mathrm{kg})\end{array}$ & $\begin{array}{c}\text { Ganho de } \\
\text { Peso }(\mathrm{kg})\end{array}$ & $\begin{array}{c}\mathrm{CA} \\
\mathrm{kg} / \mathrm{kg}\end{array}$ \\
\hline Antibiótico-Antibiótico & $4,937 \mathrm{~d}$ & $2,939 \mathrm{~b}$ & $1,68 \mathrm{bc}$ \\
Sem Levedura-Sem Levedura & $4,818 \mathrm{c}$ & $2,878 \mathrm{c}$ & $1,67 \mathrm{bc}$ \\
Sem Levedura-Levedura Autolisada & $4,783 \mathrm{~b}$ & $2,946 \mathrm{~b}$ & $1,62 \mathrm{ab}$ \\
Sem Levedura-Levedura Integra & $4,712 \mathrm{a}$ & $2,925 \mathrm{~b}$ & $1,61 \mathrm{ab}$ \\
Levedura Autolisada - Sem Levedura & $4,727 \mathrm{a}$ & $2,924 \mathrm{~b}$ & $1,62 \mathrm{ab}$ \\
Levedura Autolisada - Levedura Autolisada & $5,081 \mathrm{e}$ & $2,969 \mathrm{~b}$ & $1,71 \mathrm{c}$ \\
Levedura Autolisada - Levedura Integra & $4,794 \mathrm{~b}$ & $2,963 \mathrm{~b}$ & $1,62 \mathrm{ab}$ \\
Levedura Hidrolisada - Sem Levedura & $4,762 \mathrm{~b}$ & $2,958 \mathrm{~b}$ & $1,61 \mathrm{ab}$ \\
Levedura Hidrolisada - Levedura Autolisada & $4,710 \mathrm{a}$ & $3,024 \mathrm{a}$ & $1,56 \mathrm{a}$ \\
Levedura Hidrolisada - Levedura Integra & $4,774 \mathrm{~b}$ & $3,012 \mathrm{a}$ & $1,58 \mathrm{a}$ \\
\hline Probabilidade & 0,048 & 0,041 & 0,037 \\
\hline
\end{tabular}

Estes resultados estão possivelmente associados ao desempenho superior que os animais suplementados com a levedura hidrolisada obtiveram na fase inicial. Segundo Rutz et al. (2006), os nucleotídeos aumentam a relação vilosidade:cripta o que amplia a superficie absortiva aumentando assim a capacidade de digestão e absorção dos nutrientes e estimulam o sistema imunológico das aves, e a colonização benéfica do trato gastro intestinal destes animais, o que foi corrobado por Lopes et al. (2011) ao encontrar aumento da altura de vilos e relação vilos cripta do jejuno com a utilização de ate $5 \%$ de levedura de cana de açúcar.

Haldar et al. (2001) ao submeter frangos de cortes a temperaturas elevadas e desafio por salmonela alimentados com dietas contendo leveduras, obteve melhor ganho de peso, menor colonização no trato digestivo por $E$. colli, melhor resposta de imunidade humoral e aumento do tamanho dos vilos.

A suplementação de levedura hidrolizada ate os 14 dias e sem suplementação ate o abate não teve o mesmo desempenho dos demais tratamentos com a utilização de levedura hidrolizada na fase inicial, possivelmente devido a falta de aditivo na fase final da criação, que leva a queda de desempenho pois deixa o trato intestinal desprotegido. 
As características de carcaça não foram afetadas pelos tratamentos estudados (Tabela 6). Estes resultados estão de acordo com aqueles encontrados por Silva et al. (2003) que não constatou diferença em características de carcaça e índice de gordura corporal ao utilizar levedura na dieta de frangos de corte. Entretanto Albino et al. (2006) constatou que o uso de aditivos melhora o rendimento de cortes e diminui a gordura abdominal em frangos de corte.

Os resultados encontrados neste trabalho demonstram um efeito positivo do uso de leveduras na dieta de frangos de corte. $\mathrm{O}$ melhor programa adotado será aquele que trouxer melhor resposta zootécnica dos animais. No presente estudo, o melhor desempenho das aves foi observado na combinação de uso da levedura hidrolisada e autolisada e demonstrou ser uma boa alternativa ao uso de antibióticos promotores de crescimento. Embora não tenha ocorrido efeitos sobre as características de carcaça, os benefícios alcançados com através do desempenho das aves demonstram a efetividade da levedura em promover uma resposta positiva com a sua utilização na dieta.

Tabela 6 - Características de carcaça de frangos de corte alimentados com diferentes programas nutricionais no período de 1 a 42 dias

\begin{tabular}{lccc}
\hline Tratamento & Carcaça, \% & Peito, \% & Pernas, \% \\
\hline Antibiótico-Antibiótico & 72,87 & 28,13 & 29,33 \\
Sem Levedura-Sem Levedura & 72,78 & 26,12 & 30,52 \\
Sem Levedura-Levedura Autolisada & 71,94 & 29,03 & 29,70 \\
Sem Levedura-Levedura Integra & 72,07 & 29,07 & 28,73 \\
Levedura Autolisada - Sem Levedura & 72,99 & 29,02 & 30,45 \\
Levedura Autolisada - Levedura Autolisada & 73,44 & 28,26 & 29,70 \\
Levedura Autolisada - Levedura Integra & 71,85 & 27,40 & 29,52 \\
Levedura Hidrolisada - Sem Levedura & 73,22 & 27,90 & 30,12 \\
Levedura Hidrolisada - Levedura Autolisada & 73,12 & 28,69 & 29,25 \\
Levedura Hidrolisada - Levedura Integra & 74,89 & 27,33 & 29,30 \\
\hline P & 0,713 & 0,604 & 0,887 \\
\hline
\end{tabular}




\section{CONCLUSÃO}

Baseado no que vimos no presente trabalho, no caso da utilização da levedura na fase inicial, recomenda-se no período de 1 a 14 dias a utilização de levedura hidrolizada, pois a mesma apresentou melhor viabilidade de uso na dieta. Neste período também pode ser substituído o promotor de crescimento pela levedura autolizada sem prejuízos ao animal.

Para um programa contínuo de utilização de leveduras, recomenda-se a combinação do uso da levedura hidrolizada no período de 1 a 14 dias e de levedura autolizada no período de 15 a 42 dias e não se recomenda a utilização de uso de levedura autolizada em toda a fase de criação pois esta apresentou o pior resultado comparado aos demais. 


\section{REFERÊNCIAS}

ALBINO, L. F. T.; FERES, F. A.; ROSTAGNO, H. S.; GOMES, P. C.; COSTA, C. H.; DIONIZIO, M. A.; JÚNIOR, J. G. V.; CARVALHO, D. C. O. Uso de prebióticos à base de manoligossacarídeos em rações para frangos de corte. Revista Brasileira de Zootecnia, $v$. 35, n. 3, p. 742-749, 2006.

ASSIS, E. M. Componentes da parede celular de leveduras: proteínas e polissacarídeos de interesse das indústrias farmacêuticas e de alimentos. In: WORKSHOP PRODUÇÃO DE BIOMASSA DE LEVEDURA: UTILIZAÇÃO EM ALIMENTAÇÃO HUMANA E ANIMAL, 1996, Campinas, SP. Anais... Campinas: ITAL, 1996, p. 41-51.

BARBALHO, R. L. C. Suplementação de levedura Hidrolisada (hilyses) nas dietas de frango de corte. 2009. 59 f. Dissertação (Mestrado em Zootecnia) - Faculdade de Medicina Veterinária e Zootecnia, Universidade de São Paulo, Pirassununga, 2009.

BIGGS, P.; PARSONS, C. M. The effects of grobiotic-p on grown performace, nutrient digestibilities and cecal microbial populations in young chicks. Poultry Science, v. 8, n. 1580, p.1796-1803, 2002

BRONK, J. R.; HASTEWELL, J. G. The transport of pyrimidines into tissue rings cut from rat small intestine. The Journal of Physiology v. 382, p. 475-488, 1987.

BUTOLO, J. E. Valor nutricional da levedura. In: SEMINÁRIO DE PRODUÇÃO E COMERCIALIZAÇÃO DE LEVEDURA, 2., 1991, Piracicaba. Anais... Piracicaba: Cooperativa de Produtores de Cana, Açúcar e Álcool do Estado de São Paulo, 1991. p. 1-6.

CARVER, J. D.; Dietary nucleotides: cellular immune, intestinal and hepatic system effects. The Journal of Nutrition v. 124, p. 144-148, 1994.

DIONIZIO, M. A.; BERTECHINI, A. G.; KATO, R. K.; TEIXEIRA, A. S. Prebióticos como promotores de crescimento para frango de corte- desempenho e rendimento de carcaça. Ciência Agrotécnica, v. 7, n. 1580, p.1580-1587, 2002.

FERREIRA, S. R.; MURAKIMI, A. E.; SIQUEIRA, T. G. V.; SANTOS, J. M. G.; POTENÇA, A.; SANTOS, T. C. Níveis crescentes de parede de levedura sobre a resposta imune celular e perfil hematológico de frangos de corte. Revista Pesquisa Veterinária Brasileira, v. 29, p. 725-730, 2009.

GENEROSO, R. A. R.; GOMES, P. C.; ROSTAGNO, H. S.; ALBINO, L.F.T.; BARRETO, S.L.T.; BRUMANO, G. Composição química e energética de alguns alimentos para frangos de corte em duas idades. Revista Brasileira de Zootecnia, v. 37, n. 7, p.1251-1256, 2008. 
HALDAR, S.; GNOSH, T. K.; BEDFORD, M. R. Effects of yeast (Saccharmyces Cerevisiae) and yeast protein concentrate on production performace of boiler chickens exposed to heat stress and challenged with Salmonella enteritidis. Animal Feed Science and Technology, v.10, n. 1016, p. 61-71, 2011.

INGLEDEW, W. M. Yeast-could you base a business on this bug? In: ANNUAL SYMPOSIUM, 15., 1999. Nottingham, UK. Proceendings... Nottingham, UK.: Nottingham University Press, 1999. p. 27-47.

KULKARNI, A. D.; RUDOLPH, F. B.; VAN BUREN, C. T. The role of dietary sources of nucleotides in immune function: a review. The Jorunal of Nutrition, v. 124, p. 1442-1446, 1994.

LOPES, C. C.; RABELO, C. B. V.; SILVA, V. A. J.; HOLANDA, M. C. R.; ARRUDA, E. M. F.; SILVA, J. C. R. Desempenho, digestibilidade, composição corporal e morfologia intestinal de pintos de corte recebendo dietas contendo levedura de cana de açúcar, Acta Sientiarum Animal Sciences, v. 33, n. 1, p. 33-40, 2011.

MACHADO, D. A. V.; SARTIRI, J. R.; PEZZATO, A. C.; FASCINA, V. B.; MADEIRA, L. A.; CARRIJO, A. S.; CRUZ, V. C. Levedura (Saccharomyces Cerevisiae) Spray-Dry, Autolizada e parede celular de levedura na alimentação de frango de corte. Veterinária e Zootecnia, v. 102, n. 5716, p. 541-551, 2010.

MAIORKA, A.; SANTIN, E.; SUGETA, S. M.; ALMEIDA, J.G; MACARI,M.Utilização de prebióticos, probióticos ou simbióticos em dietas para frango. Revista Brasileira Ciência Avícola, v. 3, n. 1, p.1050-1063, 2001

MALONEY, D. Yeasts. In: KROSCHWITZ, J. I.; HOWE-GRANT, M. (Ed.). Kirk-Othmer encyclopedia of chemical technology. 4th ed. d New York, NY.: John Wiley and Sons, Inc., 1998. p. 761-788.

MATEO, C. D.; DAVE, R.; STEIN, H. H. Effects of supplemental nucleosides for newly weaned pigs. The Jornal of Animal Science. v. 82, p. 71, 2004. Supplement, 2.

MORALES, L. R.; AUCLAIR, E.; GRACIA, F. Effects of supplemental nucleosides for newly weaned pigs Use of yeast cell walls; P-1, 3/1, 6-glucans and mannoproteins in broiler chickens diets. Poutry Science, v. 88, n. 60, p. 1-7, 2001.

MOREIRA, J. A.; MIYADA, V. S.; MENTEN, J. F. M. Uso da Levedura Desidratada como Fonte de Proteína para Suínos em Crescimento e Terminação. Revista Pesquisa Veterinária Brasileira, v. 27, n. 6, p. 1160-1167, 1998.

NUNES, J. K.; MAIER, J. C.; ROSSI, P.; DALMANN, P. R.; ANCIUTI, M. A.; RUTZ, F.; SILVA, J. G. C. Suplementação de extrato de levedura na dieta de poedeiras comerciais: desempenho produtivo. Ciência Animal Brasileira, v. 9, n. 2, p. 357-364, 2008. 
OLIVER, C. E.; BAUER, M. L.; ARIAS, C. M. D. J.; KELLER, W.L.; PARK, C.S Influence of dietary nucleotides on calf health. The Jornal of Animal Science, v.81, p. 136, 2003. Supplement, 1.

RIBEIRO, R. P.; FLEMIMING, J. S.; BACILA, A. R. Uso de levedura (Saccharomyces cerevisae), ácidos orgânicos e avilamicina na alimentação de frangos de corte. Veterinary Science, v. 13, n. 3, p. 2010-2017, 2008.

RUTZ, F.; ANCIUTI, M. A.; RECH, J. L.;GONÇALVES, S. M.; DELGADO, A. D.; ROSA, E. R.; ZAUK, N.; RIBEIRO, C. L. G.; SILVA, R. R.; PALNANN P. R. Desempenho e características de carcaça de frangos de corte recebendo extrato de levedura na dieta. Ciência Animal Brasileira, v. 7, n. 4, p. 349-355, 2006

RUTZ, F.; RECH, J. L.; XAVIER, E. G.; ANCIUTI, M.A.; ROSSI, P. Cuidados críticos na nutrição inicial de aves: alternativas para melhorar o desempenho e o papel essencial dos nucleotídeos. In: SIMPÓSIO BRASILEIRO DA INDÚSTRIA DE ALIMENTAÇÃO ANIMAL, 2.; RONDA LATINO AMERICANA DA ALLTECH, 15., 2005, Curitiba. Anais... Curitiba: Alltech Biotechnology, 2005. p. 19-39.

SALATI, L. M.; GROSS, C. J.; HENDERSON, L. M.; SAVAIANO, D.A. Absorption and metabolism of adenine, adenosine-5'-mono-phosphate, adenosine and hypoxanthine by the isolated vascularly perfused rat small intestine. The Journal of Nutrition, v. 114, p. 753-760, 1984.

SANDERSON, I. R.; HE, Y. Nucleotide uptake and metabolism by intestinal epithelial cells. The Jornal of Nutrition v. 124, p. 131-137,1994.

SAS. INSTITUTE INC. SAS System for Microsoft Windows. Release 6.12. Cary, NC.: SAS, 2002.

RIBEIRO, R. P.; FLEMINNING J. S.; BACILA, A. R. Utilização de diferentes níveis de levedura (Saccharomyces Cerevisiae), parede de levedura (SSCW), ácidos orgânicos e avilamicina na alimentação de frangos de corte. Veterinary Science, v. 13, n. 3, p. 20102017, 2008.

SILVA, V. K.; AMOROSO, L.; FUKAYMA, E. H.; DOURADO, L. R. B.; MORAIS, V. M. B. Digestibilidade do extrato de leveduras em frangos de corte. Revista Pesquisa Veterinária Brasileira, v. 38, n. 10, p. 1969-1973, 2009.

SILVA, V. K.; SILVA, J. D. L.; GRAVENA, R. A.; MARQUES, R. H.; HADA, F. H.; MORAES, V. M. B. Desempenho de frango de corte de 1 a 21 dias de idade alimentados com rações contendo extrato de levedura e prebióticos e criados em diferentes temperaturas.

Revista Brasileira de Zootecnia, v. 38, n. 4, p.690-696, 2009. 
SUCUPIRA, F. S.; FLUENTS, M. F. F.; FREITS, E. R.; BRAZ, N. M.; Alimentação de codornas de postura com rações contendo levedura de cana-de-açúcar. Revista Ciência Avícola, v. 37, n. 2, p. 528-532, 2007.

TIBBETTS, G. W. Nucleotides from yeast extract: potential to replace animal protein sources in food animal diets. In: ANNUAL SYMPOSIUM OF NUTRITIONAL BIOTECHNOLOGY IN THE FEED AND FOOD INDUSTRIES, 18., 2002, Nottinghan. Proceedings... Nottinghan: University Press, 2002. p. 435-443.

UAUY, R. Dietary nucleotides and requirements in early life. In: LEBENTHAL, E. (Ed.). Textbook of gastroenterology and nutrition in infancy. . New York, NY, Raven Press, Ltd, 1998. p. 265-280.

VOET, D.; VOET, J. G. Nucleotide metabolism. In: ROSE, N. (Ed.). Biochemistry. 2nd ed. New York, NY.: John Wiley and Sons, Inc., 1995. p. 795-797.

YONEMURA, C. Y. Efeitos da utilização de levedura hidrolisada como fonte de nucleotídeos sobre o desempenho e imunidade de frango de corte. 2011 . $71 \mathrm{f}$. Dissertação (Mestrado em Zootecnia), Faculdade de Medicina Veterinária e Zootecnia, Universidade de São Paulo, Pirassununga, 2011.

ZHANG, A.W.; LEE, B. D.; LEE, S. K.; LEE, K. W.; AN, G. H.; SONG, K. B.; LEE, C. H. Effects of yeast(Saccharomyces cerevisiae) cell components on growth performance, meat quality, and ileal mucosa development of broiler chicks. Poultry Science, v. 84, n. 7, p. 1015$1021,2005$. 